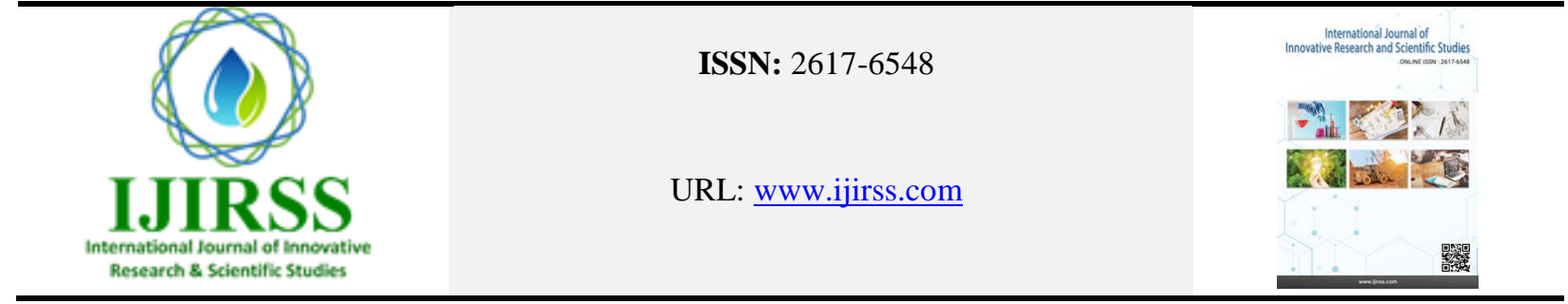

\title{
The Impact of Modern Technology in the Teaching and Learning Process
}

\author{
Siyamoy Ghory ${ }^{1 *}$, Hamayoon Ghafory ${ }^{2}$ \\ ${ }^{1}$ Department of Information Technology, Faculty of Computer Science, Parwan University, Charikar, Afghanistan \\ ${ }^{2}$ Department of Information System, Faculty of Computer Science, Shaheed Prof. Rabbani Education University, Kabul, Afghanistan \\ *Corresponding author: Siyamoy Ghory (siyamoyghoury@gmail.com)
}

\begin{abstract}
The advancement of technology has had an influence on every part of our lives, from banking to the way we connect with one another. Indeed, technology has become an essential component of sustaining civilization, and its incorporation into education is consequently unavoidable. Technology not only gives students access to a plethora of online materials, but it also helps them study. The majority of colleges and educational institutions have already begun to use technology into their teaching techniques. This paper provides in-depth on the effect and impact of the modern technology in the teaching and learning process through reviewing various secondary data. Education has been transformed by technological advancements. The significance of technology in classrooms cannot be overstated. Indeed, the introduction of computers into education has made it simpler for instructors to transfer information and for pupils to retrieve it. The integration of technology into education ecosystem has made the and learning processes more entertaining.
\end{abstract}

Keywords: Technology Impact, Learning, Teaching Process, Education.

DOI: $10.53894 /$ ijirss.v4i3.73

Funding: This study received no specific financial support.

History: Received: 12 April 2020/Revised: 21 May 2021/Accepted: 2 June 2021/Published: 18 June 2021

Licensed: This work is licensed under a Creative Commons Attribution 4.0 License $(\mathrm{cc}) \mathrm{JY}$

Acknowledgement: Both authors contributed to the conception and design of the study.

Competing Interests: The authors declare that they have no conflict of interests.

Transparency: The authors confirm that the manuscript is an honest, accurate, and transparent account of the study was reported; that no vital features of the study have been omitted; and that any discrepancies from the study as planned have been explained.

Ethical: This study follows all ethical practices during writing.

\section{Introduction}

The twenty-first century is frequently seen as a technological period. Today, technology is extremely vital in our lives. It is seen as the bedrock upon which an economy's progress is built. In present era, an enterprise that is not technologically advanced would never grow. This is because technology has made our work significantly easier and less time consuming. Technology has an impact on every sector, one of which is education [1]. With the widespread adoption of modern digital technology, information communication technologies, Networking technologies, digital photography, and other technologies, as well as the widespread use of multiple technological innovations in life and learning, information technology has altered people's learning - teaching styles, and has had a substantial effect on teaching in all areas [2]. Educational technology is a systematic and organized process of applying modern technology to improve the quality of education [3]. It is a In a classroom, students are frequently overwhelmed with information that they must quickly absorb and make sense of. This, however, might leave individuals feeling overwhelmed and perplexed by notions. Pupils now have access to a vast amount of Internet resources, which motivates them to undertake investigation and therefore develop 
self-sufficiency [4]. Several developing nations have historically made significant contributions to the advancement of science and technology, with some serving as the cradle of human civilization [5, 6]. Several initiatives aim to promote precollege students' knowledge, enthusiasm, and engagement in scientific and technical subjects [7, 8] Additionally, it facilitates learning by making ideas more digestible, such as through the use of an instructional film. It is critical to recognize that many learning styles exist, and that standard schooling may not be able to accommodate them all. The advantage of technology in education is its simplicity and accessibility have an influence on and benefit both the learner and the instructor. A teacher, for example, might invite students to complete an online quiz that provides fast feedback, saving the instructor time that would otherwise be spent grading and reviewing each work. Technology saves instructors' time and money while also allowing students to stay on top of their education by providing constant access to information, such as checking deadlines or emailing a teacher with questions at any time of day [9]. Technological innovations, like the Internet, open up latest avenues for education and learning at all educational attainment. Several colleges are now working to blend acceptable technology into college classes [10]. Many colleges are now making a determined effort to incorporate appropriate technology into their teaching and learning activities [11]. In this article, we will look at the influence of technology on the educational process as well as its benefits in the learning ecosystem. One reason for the classroom usage of technology is to train students to meet the demands of job seekers. We conducted a literature study and gathered data from secondary sources such as journal articles, conference papers, and personal experiences. To ensure the success of our study, we developed different research questions that encourage readers to learn about the implications and consequences of technology on educational environments. This study will provide suitable answers to the following questions.

Table-1.

\begin{tabular}{c|l|l}
\multicolumn{1}{c}{ Research questions. } & \multicolumn{1}{c}{ Questions } & \multicolumn{1}{c}{ Motivations } \\
\hline No. & How technology influence the learning process? & $\begin{array}{l}\text { These questions aim to describe the } \\
\text { importance and advantages of technology on } \\
\text { learning process. }\end{array}$ \\
\hline 2 & Will technology assist pupils in thinking critically? & $\begin{array}{l}\text { This question encourages students to engage } \\
\text { with technology and provide innovative } \\
\text { solutions to specific problems. }\end{array}$ \\
\hline 3 & $\begin{array}{l}\text { How will technology enable students to take charge } \\
\text { of their own education? }\end{array}$ & $\begin{array}{l}\text { Students who use technology do not require } \\
\text { an individual mentor to guide and educate } \\
\text { them. The technology itself enables kids to } \\
\text { study and learn. }\end{array}$ \\
\hline
\end{tabular}

\section{Motivation}

As we all know, technology plays a critical part in almost every part of life today. The education environment has witnessed enormous improvements in quality as a result of incorporating technology into its curriculum. The purpose of this study is to determine the most significant effect of technology on strengthening the educational process via the employment of various and cutting-edge technologies.

\section{Education and Modern Technologies}

The objective of technology in a typical educational environment is to enhance the education of knowledge and skills via enhanced efficiency and effectiveness. To conduct a thorough examination of this concept, we must first define a few concepts. The phrase efficiency refers to the rate at which humans acquire knowledge, whereas the term effectiveness refers to the quantity of given knowledge that is operationally learned. When technology is used directly to a learning environment, such as a school, both students and teachers can be considered as learners. Thus, we may assume that any improvement in instructor knowledge and use results in greater student learning. At the end of the day, technology should be used to raise student achievement in classrooms [12,13]. According to the newest insights into how current students choose to use technology and how technology impacts their learning, it was discovered that when students utilize current equipment, technology, and tools, their learning and interaction rise. Additionally, they find it far more engaged and entertaining when supported by technology. Knowledge transfer becomes extremely simple, convenient, and effective. This suggests that our minds now perform more efficiently when aided by contemporary technology in any aspect of life; in this case, schooling. The reliance and dependency on such an innovation, which only makes life easier and more pleasant, is now entirely inescapable at classrooms, institutions, and campuses [14, 15]. Additionally, the evidence presented by the detractors complicates the situation. The classical argument that teachers resist technology because it is unproductive posits that computers are approximately as successful at imparting knowledge as movies or instructive broadcasts. Computers should be welcomed by educators to the extent that they differ from established technology. Indeed, research on teacher resistance indicates that many teachers' refusal to use computers is a result of a lack of resources supporting teacher technology use, not a Radical opinion in the ineffectiveness of technology the analyzed data from one of the largest studies of teacher technology use to date, the 1989 International Association for the Evaluation of Educational Achievement survey (IAEEAS) $[16,17]$. Becker reported that just one in every six teachers used computers often in the classroom, and of those who did, the majority used them mostly for drilling and practice, avoiding more complex applications. (While just $14 \%$ of 
mathematics professors used computers to demonstrate "knowledge of numerical relationships," $68 \%$ used them to demonstrate "student mastery of computing.") Nonetheless, when Becker sought to account for teachers' varying levels and types of computer use, he observed that instructors who used computers more effectively were more likely to work in schools that provided significant teacher development on computers and had technology coordinators on hand to assist instructors with persistent challenges. According to a more recent poll, the primary reason teachers are frightened of technology is a lack of computer literacy [18, 19]. Thus, teacher resistance to computer use is not insurmountable; instructors only need to be taught and encouraged before they feel ready to utilize them. Additionally, detractors contend that computer assisted instruction (CAI) studies demonstrate that computers are less cost efficient than tutoring and that technology-based education weakens the noncognitive, social components of learning. Concerning the social dimensions of learning, the limitations of CAI research have previously been explored; all that is to be mentioned is that the influence of computers on learning is contingent upon their use. If they completely replace human contact, they risk undermining the social aspects of teaching. Similarly, if they are one of several critical tools, they will still allow for significant in-person contact between pupils and lectures. At the present, the dispute over the usefulness of technology appears to be unresolved, leaving politicians uncertain about how to employ technology or even whether to invest in it at all. The study in favor of technology appears to be limited to small-scale studies with significant methodological issues; the research against technology is based on unproven allegations that computers are analogous to film strips. To some extent, the scarcity of conclusive data on technology's efficiency is due to the limitations inherent in studying it. As studied by Mandinach and Cline argue [20], highlight, the absence of controlled studies in this field reflects the reality that technology is not introduced over a set time span. The majority of experiments feature a single intervention with a distinct beginning and finish. However, implementing technology requires acquiring hardware and software, training teachers, adapting courses, and system maintenance, among other factors. As a result, this process is continuing, with no distinct beginning or end. Mandinach and Cline argue [20] that proof of technology's success must be derived from a variety of nonexperimental ways, employing a variety of procedures at a variety of stages like the classroom, the school, the campus.

\section{Application of Technology \\ 4.1. Internet Utilization}

The internet's relevance has expanded by a factor of 10 during the previous decade. Its importance in the field of education cannot be stressed at this point. Despite the dangers of fraud and drawbacks, pupils benefit from utilizing the internet. The internet has permeated nearly every facet of our life in the modern day. The world wide web is all around us, from televisions to gaming consoles to our smartphones. Pupils may discover tremendous convenience when they use the internet; they may access a variety of aid, tutorials, and other sorts of supporting information that they may use to cognitively continue expanding their understanding [3].

\subsection{Utilization of Projectors and Visual Aids}

In comparison to words, visual pictures always have a stronger attraction. Another excellent example of technology use is the use of projectors and graphics to help with learning. Leading universities worldwide today rely on outstanding PowerPoint presentations and projections to make learning engaging and exciting [21]. Within schools and colleges, the usage of technology such as projectors may significantly increase engagement and engagement, as well as motivation. Students want to view visually appealing material and anything that encourages them to think rather than simply reading text. When it comes to technology, the learning process becomes rather efficient as well [22].

\subsection{The Educational Sector's Digital Footprint}

When it comes to digital and education, the penetration of digital media into the education sector has increased in recent years. This penetration has resulted in continuous interaction with students and the availability of many forums for various types of tasks or assistance [23]. As digital technology advances, there are and will be more applications that aid kids in their development and learning [24].

\subsection{Technology-Enhanced Online Degrees}

Pursuing a degree have become a pretty typical occurrence in recent years. Individuals desire to enroll in online courses for the purpose of education and certification. The best colleges provide incredible online programs that utilize a variety of tools and the internet. This is a notion that will gain traction when more support and awareness are generated. Around the world, online degrees are becoming increasingly popular among students who work and seek flexible learning options [12]. Technology has a four-fold function in education: it is incorporated into the curriculum, serves as an educational delivery method, assists with instruction, and also serves as a means to improve the overall educational cycle. Education has shifted from passive and reactive to participatory and combative as a result of technological innovations and advancements. Education is critical in both corporate and academic environments. In the former, education or training is utilized to assist employees in performing tasks differently than they previously did. In the latter, education is oriented on instilling a sense of wonder in kids. In any scenario, technology may aid pupils in comprehending and remembering topics $[9,25]$.

\section{Factors Impacting Educational Technology}

Everybody talks about the great problem teachers face in our culture as information expands at a breakneck pace. Teachers must learn how to incorporate current technologies into their instruction. As a result, these new technologies raise 
the demand for teacher training. According to Blignaut [26], teacher attitudes regarding computers are critical to the effective use of Information Communication Technology (ICT) in education. They emphasized that instructors do not always have a favourable attitude toward computers, and that their negative views may contribute to the failure of computer-based programs.

Additionally, the most often reported impediments are list in Figure 1:

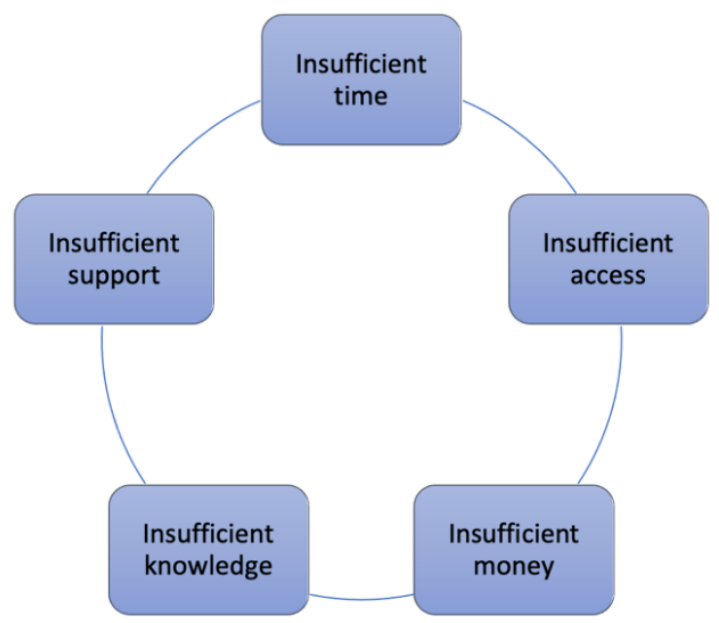

Figure-1.

list of barriers [26].

The Chizmar [27], also mention dependability as a hurdle. Reliability issues included device malfunctions, incompatibility of home and school software, insufficient or slow broadband connections, and out-of-date software that is mostly available at school, while students/educators have more current software at home.

\section{The Educational Impact of Information Technology}

ICT has the ability to expand access to education while also increasing its relevance and quality. The Wakil, et al. [28] argued that ICT has a profound effect on education in terms of knowledge acquisition and absorption for both instructors and students by promoting the following:

Active learning: Informational technologies facilitate the computing and interpretation of test data, as well as student performance reports, which are all digitized and easily accessible for inquiry. In compared to memorization- or rote-based learning, Information technology increases reading comprehension by allowing pupils to choose what they want to study at their own pace and concentrate on real-world problems.

Collaborative learning: ICT promotes contact and collaboration between students and teachers regardless of their geographical location. Additionally, it allows students to interact with individuals from many cultures and work in groups, which helps students develop their conversational skills and global awareness. According to researchers, the use of ICT often results in increased collaboration among learners both inside and outside of school, as well as a more interactive contact between students and teachers [29]. Teamwork is an interpersonal ideology and individual way of life in which leader takes ownership of their actions, which includes becoming aware of and recognizing their counterparts' skills and accomplishments [30].

Creative learning: Information Technology supports the alteration of pre-existing data and the creation of one's own knowledge in order to generate a concrete product or to accomplish a specific educational goal. Holistic learning: In contrast to the conventional classroom, where the focus is on a single aspect, information technology promotes an integrative approach to teaching and learning by reducing the synthetic boundary between theory and practice. Judgmental learning: The educational application of information technology is student-centered and provides meaningful feedback through a range of interactive features. Instead of regurgitation and rote learning, information technology helps students to investigate and learn in innovative ways that are supported by postmodern theories of learning.

\section{The Positive Impact}

\subsection{Improved Education and Teaching}

- Technological advancements such as digital cameras, projectors, mind training software, laptops, Power point presentations, and 3D visualization tools have all become valuable tools for instructors in assisting pupils in quickly grasping a topic.

- It must be realized that visual explanations of topics engage pupils and make learning more interesting. They are able to participate more actively in class, and professors have the opportunity to make their lessons more dynamic and engaging [1].

\subsection{Internationalization}


- When kids attend school in various regions of the state, they can virtually "meet" their peers without exiting the learning space.

- Certain websites, like www.udemy.com, assist students in learning foreign languages online by matching them with a tutor from another nation [28].

\subsection{Free From Geographical Restrictions}

- Mostly with emergence of online degree programs, students are no longer required to be physically present in class. Numerous overseas institutions have begun providing students the option of enrolling in online degree programs.

- In the current day, distance education and online education have become a vital part of the educational system [1].

\section{Negative Consequences}

\subsection{Deteriorating writing ability}

- As a result of extensive use of internet chatting and shortcuts, the writing abilities of today's youth have deteriorated significantly.

- Nowadays, youngsters rely so much on digital communication that they have completely forgotten how to improve their writing abilities.

- They lack knowledge of good word spelling, good grammatical usage, and cursive writing.

\subsection{An Increase in Cheating Incidents:}

- Technological advancements such as graphical calculators, high-tech watches, small cameras, and similar equipment have become excellent tools for test cheating.

- It is less risky for children to write calculations and notes on graphing calculators.

\subsection{Inability to concentrate}

- SMS, or text messaging, has become a popular activity for many students. Students can be observed all day and night playing with their cell phones, iPhones, or while driving, and quite frequently even in between lectures.

- Constant connectivity to the internet world has contributed to a loss of attention and concentration in academics and, to a lesser extent, sports and extracurricular activities [31].

\section{Benefits}

- It increases pupils' motivation to learn.

- Provide students with hectic schedules with the opportunity to work from home on their own timetable.

- Teach pupils new digital abilities that they may apply in the workplace afterwards.

- Reduce paper and photocopying expenses by supporting the "green revolution" idea.

\section{Inconveniences}

- Numerous professionals and experienced individuals assert that, as a result of such technology in education, kids' imaginations are harmed and their capacity to reason is diminished.

- Occasionally, it is also time intensive from the teacher's perspective.

- The installation of such technology is too expensive.

- When taken in excess, there may be health consequences.

- Some pupils lack the financial means to purchase new computer technology.

\section{Conclusion and future work}

We sought to determine the educational influence of technology on the learning process in this article. We discovered via many study findings that technology has a favorable effect on education but may also have negative consequences. Teachers and students should see this positively and work to reduce the barriers that prevent many kids and schools from reaching success. Thus, it is past time for all countries to implement a more technologically advanced education system in the future. Additionally, our findings indicate that studying and mastering through technology is more beneficial to the educational system than other courses, as it enables students to increase their knowledge in other areas. We urge other researchers to employ additional criteria for determining the usefulness of technology in educational institutions.

\section{References}

[1] R. Raja and P. Nagasubramani, "Recent trend of teaching methods in education" organised by Sri Sai Bharath College of Education Dindigul-624710," India Journal of Applied and Advanced Research, vol. 3, pp. 33-35, 2018.

[2] S. Xia, "Research on the influence of information technology on education under the background of big data," in 2020 International Conference on Intelligent Transportation, Big Data \& Smart City (ICITBS), 2020, pp. 612-616.

[3] L. Stošić, "The importance of educational technology in teaching," International Journal of Cognitive Research in Science, Engineering and Education, vol. 3, pp. 111-114, 2015.

[4] M. Simuforosa, "The impact of modern technology on the educational attainment of adolescents," International Journal of Education and Research, vol. 1, pp. 1-8, 2013. 
[5] A. Bilsel and O. Oral, "Role of education, science and technology in developing countries," presented at the Proceedings Frontiers in Education Conference, 1995.

[6] S. Martin, E. Sancristobal, R. Gil, G. Diaz, M. Castro, and J. Peire, "Engineering education: Importance and relevance of ubiquitous technologies " presented at the 2011 IEEE GCC Conf. Exhib, 2011.

[7] M. Riojas, S. Lysecky, and J. Rozenblit, "Educational technologies for precollege engineering education," EEE Trans. Learn. Technol, pp. 20-37, 2012.

[8] Y. Li and J. Qian, "Cases of higher education changing impacted by information technology," in 2009 International Conference on Engineering Education (ICEED), 2009, pp. 207-208.

[9] OBS, "Impact of technology on education, Online business school," 2021.

[10] J. M. Brill and C. Galloway, "Perils and promises: University instructors' integration of technology in classroom-based practices," British Journal of Educational Technology, vol. 38, pp. 95-105, 2007.

[11] M. F. Fass, "Using the internet to enhance biology education: Suggestions for the novice," Bioscene, vol. 24, pp. 7-12, 1998.

[12] K. Courville, "Technology and its use in education: present roles and future prospects," Online Submiss, pp. 1-19, 2011.

[13] A. Lekka, M. Tsironi, and J. Pange, "New trends of information and communication technologies in education," in 2015 International Conference on Interactive Mobile Communication Technologies and Learning (IMCL), 2015, pp. 389-389.

[14] D. J. Gurahian, "Does it compute?," Mod. Healthc, vol. 39, 2009.

[15] S. R. Das and S. Mohapatra, "Social and public impact of ICT enabled education," in 2008 International Conference on Information Technology, 2008, pp. 300-303.

[16] H. J. Becker, "Analysis and trends of school use of new information technologies. Prepared for the office of technology assessment," presented at the U.S. Congress, Univ. California, Dep. Educ, 1994.

[17] X. Fu, "The application of artificial intelligence technology in college physical education," in Proc. - 2020 Int. Conf. Big Data, Artif. Intell. Internet Things Eng. ICBAIE 263-266, 2020.

[18] L. D. Rosen and M. M. Weil, "Computer availability, computer experience and technophobia among public school teachers," Computers in Human Behavior, vol. 11, pp. 9-31, 1995.

[19] R. K. Jones and E. Wang, "Experiences with an engineering technology course for education majors," in Proc. - Front. Educ. Conf., 2001, pp. 4-8.

[20] E. B. Mandinach and H. F. Cline, "It won't happen soon: Practical, curricular, and methodological problems in implementing technology-based constructivist approaches in classrooms," in Computers as Cognitive Tools, volume two: No More Walls, ed: Routledge, 2020, pp. 377-395.

[21] X. Vila, A. Riera, E. Sanchez, M. Lama, and D. L. Moreno, "A PDA-based interface for a computer supported educational system," in Proceedings 3rd IEEE International Conference on Advanced Technologies, 2003, pp. 12-16.

[22] M. Amin, M. Azim, and M. Kalam, "The benefit of using multimedia projector in English Language teaching classroom," International Journal of Social Sciences \& Humanities, vol. 3, pp. 62-76, 2018.

[23] Y. Surmelioglu and S. S. Seferoglu, "An examination of digital footprint awareness and digital experiences of higher education students," World J. Educ. Technol. Curr. Issues, vol. 11, pp. 48-64, 2019.

[24] D. Thakkar, "Assessing the digital footprint and suggesting social media marketing plan for educational," vol. 4, pp. 96-140, 2020 .

[25] J. Sun, "Solving strategies research for the negative impact of computer technology on education," in 2010 Second International Workshop on Education Technology and Computer Science, 2010, pp. 671-674.

[26] A. Burger and P. Blignaut, "A computer literacy course may initially be detrimental to students' attitudes towards computers," in Proceedings of the 2004 Annual Research Conference of the South African institute of Computer scientists and Information Technologists on IT Research in Developing Countries, 2004, pp. 10-14.

[27] D. Hizmar, What do faculty want?. Educause quarterly vol. 24: John \& Williams, 2001.

[28] K. Wakil, D. Muhamad, K. Sardar, and S. Jalal, "The impact of teaching ICT for developing education systems," Int. J. of Adv. Res, vol. 5, pp. 873-879, 2017.

[29] A. Alkahtani, "The challenges facing the integration of ICT in teaching in Saudi secondary schools," International Journal of Education and Development using ICT, vol. 13, pp. 32-51, 2017.

[30] T. Panitz, A definition of collaborative vs cooperative learning. UK: London Metropolitan University, 1996.

[31] S. Al-Senaidi, L. Lin, and J. Poirot, "Barriers to adopting technology for teaching and learning in Oman," Computers \& Education, vol. 53, pp. 575-590, 2009. 